\title{
Using Self-Assessment as a Tool for English Language Learning
}

\author{
Mohd Hafizuddin Mohamed Jamrus ${ }^{1} \&$ Abu Bakar Razali ${ }^{2}$ \\ ${ }^{1}$ Academy of Language Studies, Universiti Teknologi MARA (UiTM), Kampus Rembau, Negeri Sembilan, \\ Malaysia \\ ${ }^{2}$ Faculty of Educational Studies, Universiti Putra Malaysia (UPM), Serdang, Selangor, Malaysia \\ Correspondence: Abu Bakar Razali, Faculty of Educational Studies, Universiti Putra Malaysia (UPM), 43400 \\ Serdang, Selangor, Malaysia.
}

Received: September 10, 2019 Accepted: October 23, 2019 Online Published: October 25, 2019

doi: 10.5539/elt.v12n11p64 URL: https://doi.org/10.5539/elt.v12n11p64

\begin{abstract}
A very important element of formative assessment is giving and receiving feedback. However, most teachers face difficulty in giving students feedback due to various reasons, such as the large number of students in class that makes it time consuming for them to do so. Fortunately, students themselves can be excellent sources of feedback through self-assessment, through which the students would reflect on the quality of their work, judge the degree to which their work reflects explicitly stated goals or criteria, and revise their work if necessary. Under the right conditions, student self-assessment can provide accurate, useful information to promote learning. Self-assessment can also be effective in English language learning, such as: motivating students to learn and reflect on their own English learning; promote critical thinking and reflective practices in learning English; scaffold knowledge of English learning from different English language skills; develop a sense of autonomy in their own learning English; and foster commitment in learning English among many others. This conceptual paper thus seeks to explore the potentials of using self-assessment in English language learning. In this paper, the concept and underlying principles of self-assessment will be introduced. Next, the review of past studies on self-assessment in the context of teaching and learning English as a second or English as a foreign language (ESL/EFL) will be explained. Later, the advantages and disadvantages of using self-assessment in the classroom will be discussed. In the final section, recommendations will be given for the implementation of self-assessment in learning English as a second language (ESL) classrooms.
\end{abstract}

Keywords: assessment for learning, English as a second language (ESL), Self-assessment, Language learning

\section{Introduction}

In a typical modern classroom setting in many countries that regard English as a second language (ESL) class can take up to 30 to 40 students, and it is very difficult for English teachers to assess all their students' work in the classroom. This has been a problem in such settings and attention needs to be given due to the importance of feedback and assessment in monitoring learning especially in learning a second language. According to Blanche (1989), teachers have to know to what extent students can appraise their own work and performance. Advanced learners who have ample metalanguage and metalinguistic knowledge will be able to accurately appraise their language learning and they do not have to depend entirely on teachers and can instead help their teachers be more aware of their own individual learning needs.

Student assessment in language learning is one of the most important aspects especially in measuring the students' progress in learning. Accuracy of self-assessment depends a lot on the learner's own autonomy in learning the language. However, second and foreign language users are usually at a disadvantage when it comes to assessing their own learning the English language because they are not able to compare themselves with the native users of the language. When ESL and EFL learners assess themselves the reliability of their judgements might be inaccurate due to the fact that the language learning process is rather unique and complex in which various factors, such as the role of first language interference and also affective factors that play a big role in facilitating language learning. However, it must be stated here that self-assessment in learning a language is important because it is found to help English language learners to be motivated to learn and reflect on their own English learning (Adams \& King, 2006); promote critical thinking and reflective practices in learning English language (Andrade, Ying, \& Mycek, 2010); scaffold knowledge of English learning from different English language skills (i.e., reading, writing, 
listening, speaking, grammar and vocabulary) (Butler \& Lee, 2010); develop a sense of autonomy in their own learning of the English language (Blanche, 1988); and foster commitment in learning the English language (Mican \& Medina, 2015) among many others. And the goals to learning English as a second language can actually be achieved through self-assessment if the teachers and the ESL/EFL learners know what and how self-assessment can be done properly and in the correct way.

Therefore, the main aim of this paper discusses the concept of self-assessment in the context of the Malaysian educational system. In doing so, this conceptual paper discusses the concept of self-assessment and language learning. This paper discusses the underlying principles behind self-assessment and the elements that are involved in effective self-assessment and connect self-assessment to language learning; describes the concept of self-regulated learning and Krashen's Monitor model in relation to self-assessment; reviews past studies regarding self-assessment; identifies the advantages and disadvantages of using self-assessment; and lastly, provides some recommendations on using self-assessment for the Malaysian ESL/EFL classroom.

\section{Self-Assessment in English Language Learning: Underlying Principles and Key Elements}

In general, there are three underlying principles or steps in self-assessment, as suggested by Andrade and Valtcheva (2009) namely; (1) articulating expectations, (2) self-assessing, (3) revising. In the first step, the teacher not only clearly defines expectations for a task, but also explains each criterion that would be used in the self-assessment. For instance, in teaching English writing, the teacher can either outline the criteria or discuss it with the students in the class before carrying out each activity. These criteria can include ordering the importance of different aspects in writing, e.g., conventions as compared to organisation of ideas, and the allocation of marks for each aspect (Harris, 1997). With that, students can reach an agreement with the teacher on the criteria set in assessing task performance and what counts as quality work.

In the second step, students come up with initial drafts of the task given, e.g., an essay, and continually monitor their own progress on their assignments by making comparisons between their performance against the expectations laid out, and if they find that they have not met the standard, they can write short notes to remind themselves to make changes when writing their final drafts (Andrade \& Valtcheva, 2009). In the third and final step, students use the feedback to aid in their revision. Thus, students come up with a final self-assessment, which can be compared with those of their peers and the teacher. Harris (1997) further suggests that the teacher can compile a list of common mistakes made by students which can be used as another checklist for self-editing in which students are able to refer to when revising their work.

There are various elements that need to be considered when designing self-assessment tools in order for self-assessment to be carried out effectively. Andrade (1999) suggests eight features of self-assessment which are as follows:

1) Awareness of the value of self-assessment,

2) Access to clear criteria on which to base the assessment,

3) A specific task or performance to assess,

4) Models of self-assessment,

5) Direct instruction in and assistance with self-assessment,

6) Practice,

7) Cues regarding when it is appropriate to self-assess, and

8) Opportunities to revise and improve the task or performance.

In terms of construction, self-assessment is typically centered around specific tasks whereby a set of criteria are introduced clearly and models or samples are given so students can see how each criterion is linked to the task. Regarding the task, it is important for teachers to frame it in such a way that students are able to easily assess their performance after completing the task. When it comes to the criteria for assessment, Andrade and Valtcheva (2009) suggest using a rubric, whereby they say that "a good rubric describes the kinds of mistakes students tend to make, as well as the ways in which good work shines" (p. 13). Thus, students gain valuable information about what is required of them from the task, rather than having to guess what their learning objectives are and how to best meet those objectives. In addition to having an assessable task and clear criteria, providing students with models of self-assessment would make the identification and familiarising process even smoother when it comes to actually doing their own assessment; students not only understand the criteria, but see how it is applied and done in reality, which would help give them a better grasp of the assessment. 
Besides the task, criteria and models, another crucial part is the role of the teacher in implementing the self-assessment. Before even getting started on making the criteria of the self-assessment clear to students, the teacher needs to first create an awareness among students about the value of using self-assessment, otherwise, students might just see self-assessment as an additional and unnecessary task. Once students begin to see self-assessment as being useful, particularly in aiding learning, can they fully come to appreciate and have the desire to self-assess. The teacher also plays an important role in providing assistance and guiding students through using the self-assessment, so as to ensure students understand the criteria clearly and are correctly assessing themselves against those criteria given. Finally, the teacher should give students plenty of room to practice self-assessing as well as more opportunities to revise and improve on the task that they have previously completed and self-assessed on. By allowing students to do that, they become more familiar with how to accurately assess themselves and subsequently know which areas they need to work on in order to improve the quality and accuracy of their work.

\section{Self-Regulated Learning and Krashen's (1980) Monitor Model in Self-Assessment in English Language Learning}

The key aspect of self-assessment is that students typically have to reflect upon their work and make their own judgements based on a fixed set of criteria supplied by the teacher. Here, students play an active role in the whole process, thus making learning a student-centered process where the student takes charge of his/her own learning. Self-assessment is derived from the concept of self-regulated learning. According to Puustinen and Pulkkinen (2001), self-regulated learning is "an intermediate construct describing the ways in which individuals regulate their own cognitive processes within an educational setting" (p. 269). Zimmerman (1990) identifies three prevalent features that constitutes self-regulated learning which are: (1) the learner's use of self-regulated learning strategies, (2) the learner's responsiveness to self-oriented feedback about learning effectiveness, and (3) the learner's interdependent motivational processes.

In self-regulated learning, the underlying processes include not only the cognitive/metacognitive aspect, but the motivational and behavioural aspects. Self-regulated learners are highly motivated to improve in their learning progress, employ various thinking strategies such as organising, reflecting, and self-evaluating, and take concrete steps towards accomplishing their goals. In the second feature of self-regulated learning offered by Zimmerman (1990), the self-regulated learner acts upon the feedback he/she receives, or in the case of self-assessment, the feedback he/she arrives at after evaluating his/her own work, to identify the measures that should be taken so as to progress further in learning.

Besides self-regulated learning, another significant model in the concept of self-assessment is Krashen's (1980) Monitor Model (as cited in Blanche \& Merino, 1989, pp. 326-327) particularly when it comes to second language learning. In this model, Krashen makes a distinction between acquisition and learning, where acquisition occurs subconsciously through everyday communication which focuses on meaning while learning happens consciously in formal contexts where language is explicitly taught. In this model, the learned system acts as a Monitor, which can alter the output of the acquired system in that learned knowledge can be acted upon to modify utterances generated from the acquired knowledge. When considering conscious monitoring, performers are predicted to vary. On one end of the spectrum, there are "Monitor over-users," who monitor as much as possible, causing uneven performance; on the other end, "Monitor under-users" do not monitor at all despite favourable conditions (Blanche $\&$ Merino, 1989). There are various factors that seek to explain this variation, such as the learner's age, amount of formal instruction experienced, and personality, among other factors.

In relating the concept of self-regulated learning and Monitor Model to self-assessment, just before engaging in self-assessing, students generally bring their already available and acquired language knowledge to the table, which at times may not be too accurate. By drawing students' attention and awareness to a set of criteria used in the self-assessment that constitute various language features and by providing a clear explanation on how to conduct self-assessment (such as accompanied by a demonstration), students are able to more accurately pinpoint their own language mistakes and know how to correct those mistakes through self-reflection and feedback given. Thus, through self-assessment, the teacher's goal would be to constantly transform the students' learned knowledge to become acquired knowledge by specifically and consciously drawing the student directly to his/her personal language use and language system (his/her acquired system) rather than teach language in general and hope that students understand and would somehow internalise the learned knowledge by merely doing exercises/drills. Self-assessment thus enables access into students' acquired language systems directly and brings it within close proximity. Teachers then train students to be effective Monitors through their regular practice of self-assessing so that they learn how to monitor their performance in a balanced way that would aid their learning. 
By understanding the underlying principles of self-assessment, teachers, curriculum developers and policymakers (and other stakeholders) can effectively design self-assessment tools that would be in tandem with the said principles. For instance, designing a self-assessment tool that is in relation with self-regulated learning would make the teacher consider the various aspects that would appeal to the metacognitive as well as the motivational states of students. On the other hand, awareness of the Monitor Model would help teachers design the self-assessment in such a way that students are able to comfortably use the learned system (such as through the criteria stated in the assessment) as an effective monitor to aid their acquisition.

Given the potential of self-assessment in English language learning, there have been a number of studies done by numerous researchers all over the world in regards to the use of self-assessment in teaching and learning English as a second/foreign language. In the next sections the authors explain the process that was undertaken in reviewing a number of these research, report on the review of these research, and describe the advantages and disadvantages found from these studies on the use of self-assessment in English language learning. After that, the authors give some recommendations how self-assessment can be used in teaching and learning English as a second language.

\section{Reviewing the Literature}

This literature review reports on studies on the use of self-assessment specifically in language learning (i.e., English language). Several major online research databases were researched in obtaining these studies (i.e., ERIC, JSTOR, ProQuest, ScienceWiley, and SAGE). A few studies were also obtained from the Google Scholar search engine. The searches in all of these online databases were confined to the use of specific terms, such as "self-assessment in language learning," "self-evaluation in language learning," or "self-assessment in language learning." To explain, there were 743 studies found with the term "self-assessment in language learning," and 706 studies found in the electronic databases using the term "self-evaluation in language learning" and "self-assessment in language learning." With the majority of these articles found in the Internet resources being commentaries, reviews, and essays on the use of self-assessment, stringent selection of only empirical studies was done. Certain selection criteria were met to ensure that the studies were focused on the use of self-assessment in English language learning. First, the literature review focuses on only articles from peer-reviewed journals, such as Language Testing in Asia, Theory into Practice, Assessment in Education: Principles, Policy \& Practice, Educational Measurement: Issues and Practice, Language Learning, Language Teaching Research, Teaching and Teacher Education, Assessment and Evaluation in Higher Education, Review of Educational Research, ELT Journal, Innovations Education and Training International, Language Testing, Scandinavian Journal of Educational Research, Practical Assessment, Research, and Evaluation, Assessing Writing, Journal of Computer-Based Instruction, Learning Environments Research, and Educational Psychologist. Other studies done outside of this scope, that might employ different methods of research, different samples, and different types of self-assessment were not reported. Second, the studies in this literature review were selected under the notions of English language learning. Other studies that were done on self-assessment, but within umbrellas of other fields, such as sports studies and psychology were not included. Studies that suggested similar genres (i.e., reflective practice), but did not use the terms mentioned previously, were excluded from the review. These steps were taken to minimize the review of irrelevant studies which might not be suitable for this literature review.

There are altogether 23 past studies and research that has been carefully selected and chosen for this review, in order to acquire a more comprehensive and extensive understanding of the concept of self-assessment and its effects on learning, particularly on learning English as a second/foreign language. All of the 23 studies on self-assessment discuss about language education for both native and non-native speakers of the English language. They were published between the years 1989 to 2015.

\section{Review of Past Studies on Self-Assessment in English Language Learning}

It must be stated that most studies on self-assessment in teaching and learning English as a second or a foreign language tend to be done on teaching and learning of English writing. There are, however, a number of studies done on other aspects of English language, such as communication skills and reading skills.

Abolfazli and Sadeghi (2008) investigated the effect of self-assessment on Iranian undergraduate EFL students' course achievement. The researchers studied 82 participants for this research and they used Techniques and Principles in Language Teaching (Larsen-Freeman, 2006) as the instructional material in a four-unit credit course. The two other materials used were the knowledge test for pre-testing and course achievement test for post testing. The study was conducted using a semi-experimental design and the sample were randomly assigned into three groups which were self-assessment, peer-assessment, and teacher-assessment. The samples had a pre-test which measured the student's schemata on the specific course book and they were trained on how to assess themselves. The self-assessment group of students were instructed to construct, answer and assess their own work. The result 
of the study is enlightening and in favor of self-assessment, as it is shown that during the four assessments done in the study, the self-assessment group had the highest mean scores in the study. The results showed that during the four assessment series, self-assessment group had the highest mean scores in the first three followed by peer-assessment group; but for the last assessment, peer-assessment group outperformed the other groups. Therefore, the study indicated that self-assessment had an effect on Iranian university EFL students' course achievement.

Oscarson (1989) investigated the implementation of self-assessment among high school students. This study is entitled "Self-assessment of language proficiency: rationale and applications", in which the researcher provided sets of materials and activities that can be used during the implementation of self-assessment in language learning, where teachers can come up with progress cards and other record keeping devices. Oscarson (1989) explained the characteristic approach in the graded objectives movement is to define series of short-term functional goals for the students and to group these goals together in graded blocks at various levels of difficulty. The objectives were based on the previous criteria in the progress cards and record keeping devices, therefore, students would advance according to the carefully structured sequence of increasingly improved abilities and skills. The researcher also proposed teachers to use questionnaires, rating scales and checklists when conducting self-assessment with students. This approach is popular in the modern self-assessment era. This is where the students need to tick the level he finds suitable according to his estimation. Oscarson also mentioned that teacher training needs to be emphasised more. According to him, relevant training of teachers may actually constitute a prerequisite for the effective realisation of self-assessment in language learning.

Ross, Rolheiser, and Hogaboam-Gray (1999) conducted a study to examine the effects of self- assessment on 148 students across grades 4 through 6 . The study consisted of a treatment group and a control group where the former was taught how to evaluate their work over an 8 -week period. In the study, the students had to complete pre- and post-test narrative writing tasks, whereby the criteria that would be used to mark the stories were described. The students thus wrote a rough and a final copy of their work. They found that the treatment group students became more accurate in their self-evaluations than controls. Treatment students also outperformed controls on narrative writing, but the overall effect was small $(\mathrm{ES}=0.18)$. Weaker writers also improved their writing much more if they were in the treatment than the control group $(\mathrm{ES}=0.58)$. The findings of this study showed that teaching of self-assessment skills increased the accuracy of students in their own self-assessing. This was due to the teacher involved the students in rubric construction, thus gave them a clearer understanding of what was to be expected in addition to students being required to give reasons behind their self-assessments, particularly when there were differences found between their self-assessments and the teacher's judgement. Besides that, self-assessment had a larger impact on the performance of weaker students who wrote poorly at the start of the study as compared to other students. This might have been due to self-assessment training which proved to be more meaningful to weaker students in that they received more explicit feedback on how they could improve as compared to what they usually received from the teacher. Also, the rubrics might have been more oriented towards weaker performers as higher achievers already had the knowledge of what was to be expected of them in producing a quality piece of writing.

Butler and Lee (2010) also found that self-assessment had small but positive effects among young EFL learners in their English language performance. They conducted a study among $2546^{\text {th }}$ grade (elementary school) South Korean students who used self-assessments regularly for a semester in their English classes. There were two self-assessments used in this study, namely, the general self-assessment, i.e., Summative Self-Assessment (SA), which was administered at the start of the semester and once at the end to both the treatment and control group, while the second assessment, the unit-based SAs, which were employed after every textbook unit, were used only on the treatment group. In order to compare the students' language performances, the researchers administered two objective tests, i.e., the Cambridge Young Learners' English Test (CYCLE) and the Test of English at Seoul City Elementary Schools (STCYD), once at the start of the semester and once more at the end to both groups. It was found that students who did the unit-based self-assessments regularly improved on their language accuracy as compared to those who did not; however, the effect was marginal. The researchers stated that this may have been due to various factors, such as how the students did not fully understand the purposes behind self-assessing and the lack of feedback provided by the teachers.

In another study conducted by Andrade, Du, and Wang (2008) to explore whether the use of a rubric-referenced self-assessment would affect elementary school students' writing, they found that it did in fact help these students to produce more effective writing. In this study, the researchers obtained a sample of 116 participants who were in grades 3 and 4, across seven public elementary school classrooms in the United States, who volunteered to be part of the study. Because the researchers wanted to compare between the effectiveness of using a rubric in students' 
self-assessment, they divided the students into two groups, i.e., the treatment group and the comparison group. In the treatment group, the teacher first read and discussed a model story/essay with the students followed by the handing out and discussion of a written rubric whereas the comparison group did not receive any rubric. After both groups of students wrote their first drafts, only students in the treatment group used the rubric to self-assess their first drafts. Finally, both groups wrote their final drafts after receiving teacher feedback. The findings of the study suggest that when students use model papers to formulate a set of criteria for a writing task while also using a rubric for self-assessment of their first drafts, the quality of their writing is enhanced. Additionally, based on a poll done in the study, it was found that there might be no significant effect on students' work if teachers merely handed out a rubric without clearly explaining it. This means that self-assessment works best if teachers are involved, and if teachers are able to explain to their students the steps in self-assessing.

Andrade, Du, and Mycek (2010) extended Andrade, Du, and Wang's (2008) study of using rubrics, but with middle school students consisting of 5th, 6th, and 7th graders. In this study, similar conditions were replicated, such as having a treatment and comparison group and using model essays. Gender, time spent writing, grade level, prior rubric use, and previous achievement in English were also examined. The treatment involved using a model essay to scaffold the process of generating a list of criteria for an effective essay, reviewing a written rubric, and using the rubric to self-assess first drafts. The comparative condition involved generating a list of criteria and reviewing first drafts. Findings include a main effect of treatment, gender, grade level, writing time, and previous achievement on total essay scores, as well as main effects on scores for every criterion on the scoring rubric. The results suggested that reading a model, generating criteria, and using a rubric to self-assess can help middle school students produce more effective writing. In this regards, and similar to their previous study in 2008, the middle school students who used model papers to generate criteria for the writing task and proceeded to do self-assessment on their first drafts based on the written rubric displayed a higher quality in their writing.

All in all, there have been a number of studies done to find out the effectiveness of self-assessment towards students' writing. There are also other studies that investigated on whether self-assessment aid in the learning of other language skills. For instance, Chen (2008) conducted a longitudinal case study to investigate EFL students' learning of self-assessing their oral performance in English. In this study the students were closely monitored and took charge of their own learning of their oral skills. Chen found that by receiving continuous feedback from the teacher and through regular practice, students were able to self-assess their oral performances more accurately, in which their scoring more closely resembled that of their teachers'.

In another study by Duque Micán and Cuesta Medina (2017), they examined how self-assessment would influence oral skills and vocabulary development of young adult learners. In this study, the researchers made use of learning logs, field notes and audio recordings in the students' self-assessment process where much reflection was done by the students. It was found that the students not only perceived their practice of self-assessing to be beneficial in helping them improve on their fluency and vocabulary, but they showed actual improvement based on the results of their post-speaking tasks (as compared to the pre-speaking tasks conducted at the start of the study). When students self-assess their own learning, they were able to acknowledge their learning strengths and drawbacks. This practice enabled students to set learning commitments, use learning strategies that also allow them to raise awareness and take further actions, while self-monitoring. The students were able to gradually become more able to self-monitor, judge and react towards their own gains in language and learning.

Besides speaking, self-assessment has also been explored in other language areas. For instance, Baniabdelrahman (2010) investigated the effect of 11th grade Jordanian students' self-assessments on their reading comprehension performance. In this study, Baniabdelrahman used two assessment methods: The One-Minute paper, which allowed students to reflect on their understanding of each lesson (administered at the end of each lesson), and a rating-scale sheet in which a written list of performance criteria was laid out for the students to check their own performances against. He found that there was a statistically significant difference between the mean scores of the performance of the subjects of the experimental group over the period of the study compared to the mean scores of the subjects of the control group. Moreover, the results of the study reveal that there is a significant difference in variance of achievement between the two groups. The effect size of self-assessment on reading was significant. This indicates that the self-assessment method was more effective than the traditional method of assessment in improving students' reading comprehension. From the results of the students' post-reading test (as compared to their pre-test results), it was found that the students' reading comprehension improved and that the self-assessment tools had a positive effect on their understanding in reading.

\section{Discussion: Advantages and Disadvantages of Self-Assessment in English Language Learning}

Self-assessment in language learning is a relatively new concept and the effectiveness of using self-assessment is 
still being studied by scholars and academicians in the field of education. However, there are quite an abundant of research reports on successful use of self-assessment in language learning.

According to Falchikov and Boud (1989), self-assessment can be a good indicator for an important learning activity and is able to deliver incredible feedback to the student regarding their learning. In addition, McDowell (1995) mentioned that the advantage of implementing self-assessment in a language classroom is the fact that it can record the development of evaluative and critical abilities of students. This is rather helpful especially in large classrooms where teachers don't have ample time to assess every student's progress. The progress of students' learning is not being discarded in any way by using self-assessment. Additionally, the advantage of using self-assessment is that it can foster students' affective domain of ownership for their own learning. When students self-assess their own work, they take responsibility of their own learning which is important in language learning.

One of the main objectives of implementing self-assessment in language learning is to foster students' autonomy in learning, especially in language learning. In this regard, Brown (2007) states that successful mastery of a foreign language will depend to a great extent on learners' autonomous ability both to take initiative in the classroom and to continue their journey to success beyond the classroom and the teacher. Having learning autonomy will also lead to students increase in motivation and encouragement to participate actively in learning a language. When students know their strengths and weaknesses through various methods in self-assessments, such as the implementation of rubrics and criteria in any language topic, it will help them to monitor their language performance and progression.

Sluijsmans, Dochy and Moerkerke (1998) believed that self-assessment will ensure that students' thoughts and judgements are respected. This is important especially in the ESL context where students are most likely nervous and anxious in learning and practicing using English as a second language. Implementing self-assessment somehow eliminates the threat of the all-knowing teacher by giving them the authority to correct their own work according to the given rubrics and criterions. Having self-assessment as a tool for the students to better learn English will also benefit the teachers in terms of assessment and reducing their workload (Rushton et al., 1993).

Last but not least, self-assessment will increase the students' cognitive level as they need to think more deeply about their learning and learn to criticise constructively. One of the ways of learning is by making mistakes and self-assessment provides a safe platform for students to commit and make mistakes without having to worry about other peers' judgements on their product of learning. They assess their own work and take autonomy in correcting their own work which will sharpen their critical thinking skills in identifying errors and criticizing in a constructive manner.

All things considered, even though self-assessment has great potential there are several disadvantages of self-assessment, particularly if the key principles and elements of self-assessment are not attended to. The point of self-assessment is to train and engage students in a formative process in which they compare their work to clear criteria and determine how to make improvements. However, this concept of self-directed learning can be counterproductive if students are not assessing themselves honestly, in that they might take advantage of this opportunity to assess themselves according to what they desire (e.g., crediting themselves full marks when it is otherwise). There are also questions on the credibility of students in assessing themselves such as "are the students competent enough to assess their own learning?" and "are the rubrics given sufficient, adequate and clear for the student to use in their self-assessment?" In addition, according to Adams and King (1995), from the perception of many ESL/EFL students, especially those who adhere by the eastern cultures, they might place the teachers as the sage of the stage who should be responsible for conducting lessons, marking and assessing their work. In this regard, self-assessment is difficult to carry out unless this mentality among students who are used to the traditional way of assessment are somehow changed.

These disadvantages of using self-assessment in learning, if scrutinised closely, can actually be overcome if the proper guidance, training and awareness is given to students by the teacher. Despite being a relatively new concept in the field of education and language learning, self-assessment has taken the interest of many scholars and researchers. The empirical data and results showed that self-assessment was beneficial for both students and teachers in solving major problems in the classroom. However, the concept needs proper implementation by the teacher or it will result in unwanted situations for teachers and students in the classroom. Thus, it is important for teachers and students to take into account the different elements when using self-assessment.

\section{Suggestions and Recommendations for ESL/EFL Classrooms}

Self-assessment has yielded promising results in terms of students' progression and advancement in learning a language. However, to introduce and implement self-assessment in language learning for purpose of English as a second or foreign language, there are several factors that need to be carefully thought through before ESL/EFL teachers can use self-assessment in their teaching. First of all, ESL/EFL teachers need to take some time to explain 
the procedures of self-assessment, the concept of rubrics and criterions to their students. According to Banerjee and Alderson (2001), the term self-assessment is not self-explanatory and it needs time to be introduced to students who are new to this concept. Learners also need to be fully guided in their usage of the rubrics and instruments. It is also important to take into consideration certain cultures in conducting lessons in which self-assessment is used. It is also stated in Banerjee and Alderson's study that it is vital to consider the cultural influences in using self-assessment in a multicultural classroom.

The next suggestion is for ESL/EFL teachers to come up with self-evaluation forms, rubrics and instructions in the native language in order to assist the low proficient students in their understanding. In the case of the intermediate and advanced students, they might not need to translate instruction of their self-assessment in their native language; however, students with low proficiency need all the assistance they can get to ensure continuous self-evaluations in their language learning. According to Blanche and Merino (1989), the teachers need to sample, rephrase, rearrange, and supplement in such a way that they are able to reflect upon all the aspects of language learning. The authors highly suggest that educators and scholars take into consideration the conditions in which self-assessment is likely to meet with success. Ross (2006) recommended the following:

1) Define the criteria by which students assess their work,

2) Teach students how to apply the criteria,

3) Give students feedback on their self-assessments

4) Give students help in using self-assessment data to improve performance.

The authors also fully support Ross' (2006) suggestions, and we also recommend two additional conditions:

1) Provide sufficient time for revision after self-assessment, and

2) Do not turn self-assessment into self-evaluation by counting it toward a finalised grade.

Under these conditions, criteria-referenced self-assessment can ensure that all students get the kind of feedback they need in order to achieve success in their leaning. This recommendation is highly suggested to ESL/EFL teachers who want to implement self-assessment in their teaching. Successful self-assessment mostly depends on the teacher's ability to be able to instruct and provide proper materials (rubrics) to the students regarding self-assessment. Without proper training, it will be difficult for ESL/EFL teachers to conduct self-assessment. Therefore, as suggested by Oscarson (1989), another area that would seem to need an impetus in this direction is that of teacher training. Relevant training of teachers may actually constitute a prerequisite for the effective realization of student-centered evaluation techniques. It is of great importance that training of using self-assessment starts from the teacher training education and not when they are working as teachers. Rigorous training by educational institutions will provide teachers with ways to deal with possible problems that might occur such as rubrics' validity and reliability. Practice makes perfect and self-assessment implementation requires practice to be executed successful in the real classroom session.

\section{Conclusion}

Self-assessment is a unique concept which has promising values towards the education field in general, and English language learning in particular. Self-assessment can be used to deal with major problems that teachers face in teaching, such as the lack of time for assessment due to classroom settings and syllabus they need to finish. Self-assessment, with proper execution, can help a teacher manage his/her assessment better in which a large classroom can be assessed without any student left behind. However, self-assessment need to be done according to the key principles and elements properly, because if it is not done so, it can also be detrimental to students' learning as they can cheat their way through their own assessment. Furthermore, sometimes ESL/EFL students' lack of metalanguage and metalinguistic knowledge will lead to inaccurate assessment of their own work. In this regard, there are several methods in using self-assessment successfully in the ESL/EFL classroom settings, such as using progress cards, report keeping devices, questionnaires, rating scales and checklists. However, proper teacher training is also needed to ensure successful execution of self-assessment using these materials.

\section{Acknowledgment}

The researchers would like to acknowledge the Universiti Putra Malaysia (UPM) for funding this research through Geran Putra (GP/2018/9654400) Research University Grant (RUG).

\section{References}

Abolfazli, Z., \& Sadeghi, K. (2012). The effect of assessment type (self vs. peer vs. teacher) on Iranian university EFL students' course achievement. Language Testing in Asia, 2, 47-74. https://doi.org/10.1186/2229 
$-0443-2-4-47$

Adams, C., \& King, K. (1995). Towards a framework for student self-assessment. Innovations in Education and Training International, 32, 336-343. https://doi.org/10.1080/1355800950320405

Andrade, H. G. (1999). Student Self-Assessment: At the Intersection of Metacognition and Authentic Assessment. Paper presented at the Annual Meeting of the American Educational Research Association (Montreal, Quebec, Canada, April 19-23, 1999).

Andrade, H., \& Valtcheva, A. (2009). Promoting learning and achievement through self-assessment. Theory into Practice, 48(1), 12-19. https://doi.org/10.1080/00405840802577544

Andrade, H. L., Du, Y., \& Mycek, K. (2010). Rubric-referenced self-assessment and middle school students' writing. Assessment in Education: Principles, Policy \& Practice, 17(2), 199-214. https://doi.org/10.1080/ 09695941003696172

Andrade, H. L., Du, Y., \& Wang, X. (2008). Putting rubrics to the test: The effect of a model, criteria generation, and rubric-referenced self-assessment on elementary school students' writing. Educational Measurement: Issues and Practice, 27(2), 3-13. https://doi.org/10.1111/j.1745-3992.2008.00118.x

Baniabdelrahman, A. A. (2010). The Effect of the Use of Self-Assessment on EFL Students' Performance in Reading Comprehension in English. TESL-Ej, 14(2).

Blanche, P., \& Merino, B. J. (1989). Self-assessment of foreign-language skills: Implications for teachers and researchers. Language Learning, 39(3), 313-338. https://doi.org/10.1111/j.1467-1770.1989.tb00595.x

Butler, Y. G., \& Lee, J. (2010). The effects of self-assessment among young learners of English. Language Testing, 27(1). https://doi.org/10.1177/0265532209346370

Chen, Y. M. (2008). Learning to self-assess oral performance in English: A longitudinal case study. Language Teaching Research, 12(2), 235-262. https://doi.org/10.1177/1362168807086293

Droogenbroeck, F. V., Spruyt, B., \& Vanroelen, C. (2014). Burnout among senior teachers: Investigating the role of workload and interpersonal relationships at work. Teaching and Teacher Education, 43, 99-109. https://doi.org/10.1016/j.tate.2014.07.005

Duque Micán, A., \& Cuesta Medina, L. (2017). Boosting vocabulary learning through self-assessment in an English language teaching context. Assessment and Evaluation in Higher Education, 42(3), 398-414. https://doi.org/10.1080/02602938.2015.1118433

Falchikov, N. \& Boud, D. (1989). Student self-assessment in higher education: a meta analysis. Review of Educational Research, 59(4), 395-430. https://doi.org/10.3102/00346543059004395

Harris, M. (1997). Self-assessment of language learning in formal settings. ELT Journal, 51(1), 12-20. https://doi.org/10.1093/elt/51.1.12

McDowell, L. (1995). The impact of innovative assessment on student learning. Innovations Education and Training International, 32, 302-313. https://doi.org/10.1080/1355800950320402

Oscarson, M. (1989). Self-assessment of language proficiency: rationale and applications. Language Testing, 6, 1-13. https://doi.org/10.1177/026553228900600103

Patri, M. (2002). The influence of peer feedback on self-and peer-assessment of oral skills. Language Testing, 19(2), 109-131. https://doi.org/10.1191/02655322021t224oa

Puustinen, M., \& Pulkkinen, L. (2001). Models of self-regulated learning: A review. Scandinavian Journal of Educational Research, 45(3), 269-286. https://doi.org/10.1080/00313830120074206

Ross, J. (2006). The reliability, validity, and utility of self-assessment. Practical Assessment, Research, and Evaluation, 11(10). Retrieved January 11, 2007, from http://pareonline.net/getvn.asp?vD11\& nD10

Ross, J. A., Rolheiser, C., \& Hogaboam-Gray, A. (1999). Effects of self-evaluation training on narrative writing. Assessing Writing, 6(1), 107-132. https://doi.org/10.1016/S1075-2935(99)00003-3

Rushton, C., Ramsey, P. \& Rada, R. (1993). Peer assessment in a collaborative hypermedia environment: A case study. Journal of Computer-Based Instruction, 20(3), 75-80.

Sluijsmans, D., Dochy, F., Moerkerke, G. (1998). Creating a Learning Environment by Using Self-, Peer- and Co-Assessment. Learning Environments Research, 1(3), 293-319. https://doi.org/10.1023/A:1009932704458

Zimmerman, B. J. (1990). Self-regulated learning and academic achievement: An overview. Educational 
Psychologist, 25(1), 3-17. https://doi.org/10.1207/s15326985ep2501_2

\section{Copyrights}

Copyright for this article is retained by the author(s), with first publication rights granted to the journal.

This is an open-access article distributed under the terms and conditions of the Creative Commons Attribution license (http://creativecommons.org/licenses/by/4.0/). 